\title{
СРАВНИТЕЛЬНАЯ ОЦЕНКА ЭФФЕКТИВНОСТИ БЛОКАТОРОВ НАКОПЛЕНИЯ КОНЕЧНЫХ ПРОДУКТОВ ГЛИКИРОВАНИЯ РАЗЛИЧНОГО МЕХАНИЗМА ДЕЙСТВИЯ В ОТНОШЕНИИ ОСТРОГО ПОВРЕЖДЕНИЯ ЛЕГКИХ, ВЫЗВАННОГО ВИРУСОМ ГРИППА А/Н1N1PDMO9, В ЭКСПЕРИМЕНТАХ НА МЫШАХ
}

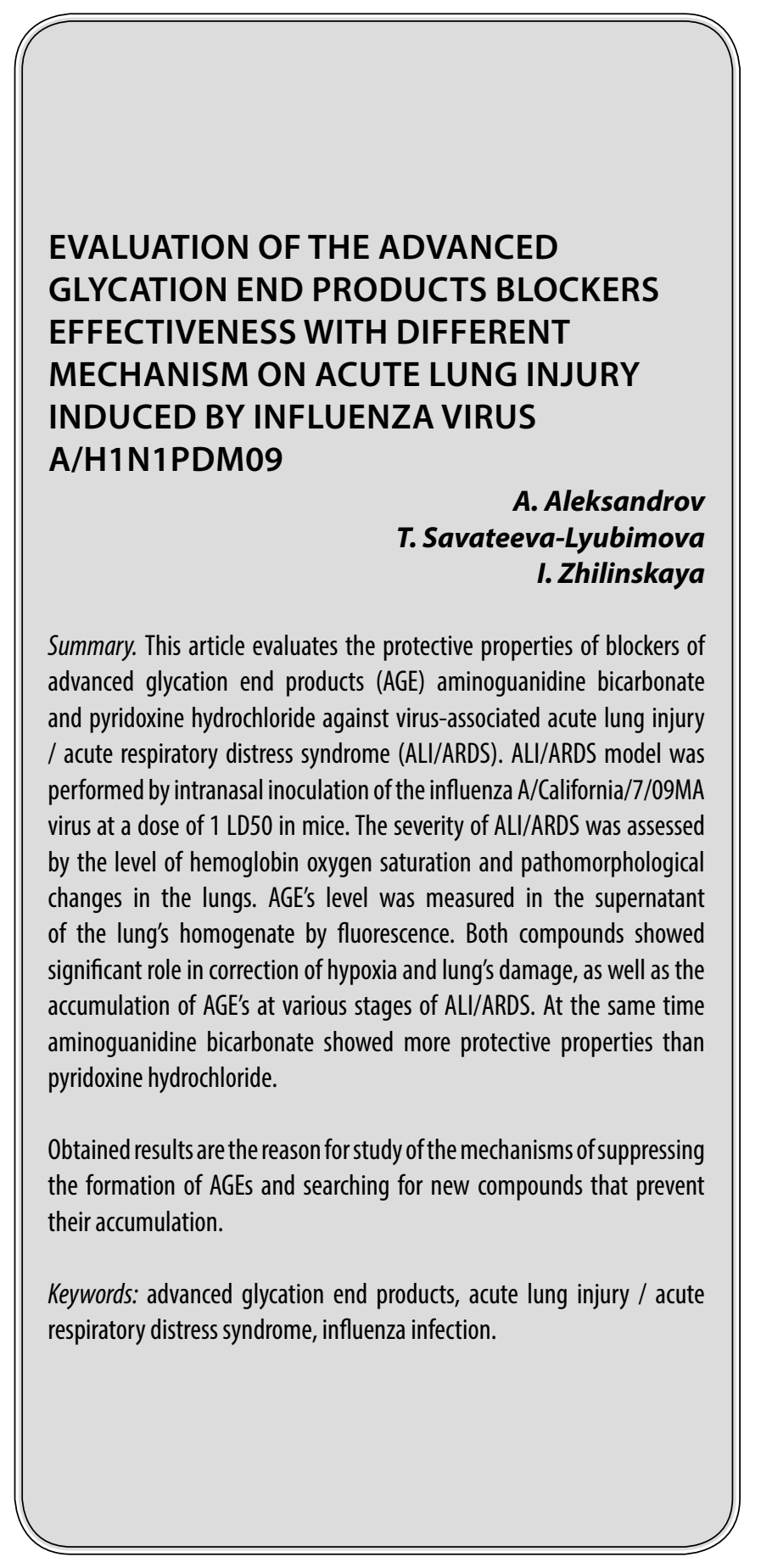

\section{Александров Андрей Георгиевич}

Аспирант, ФГБУ «НИИ гриппа им. А.А. Смородинцева» Минздрава России, Санкт-Петербург

forphchemistry@gmail.com

Саватеева-Любимова Татьяна Николаевна

Д.м.н., nрофессор, в.н.с., ФГБУ «НИИ грunna им. А.А. Смородинцева» Минздрава России, Санкт-Петербург drug_safety@mail.ru

Жилинская Ирина Николаевна Д.б.н., профессор, в.н.С., ФГБУ «НИИ грипnа им. А.А. Смородиниева» Минздрава России, СанктПетербург

irina.zhilinskaya@influenza.spb.ru

Аннотация. В статье представлены данные по сравнительной оценке протективных свойств блокаторов накопления конечных продуктов гликирования (КПГ) аминогуанидина бикарбоната и пиридоксина гидрохлорида в отношении острого повреждения легких/острого респираторного дистресс-синдрома (ОПЛ/ОРДС) у мышей, зараженных вирусом гриппа A/H1N1pdm09. Воспроизведение модели 0ПЛ/ОРДС осуществляли методом интраназальной инокуляции вируса гриппа штамма A/California/7/09MA в дозе 1 LD50. Оценку выраженности течения 0ПЛ/ОРДС проводили по величине сатурации гемоглобина кислородом и патоморфологическим изменениям в лёгких. Содержание КПГ в лёгких определяли в супернатанте гомогената органа по уровню флуоресценции. Проведённое исследование показало, что оба соединения способствовали ограничению степени гипоксии и повреждения легких, а также накопления КПГ на различных этапах формирования ОПЛ/ОРДС. По совокупности данных показателей аминогуанидин бикарбонат проявил более выраженные протективные свойства, чем пиридоксина гидрохлорид.

Полученные результаты являются основанием для углубленного изучения механизмов подавления образования КПГ и поиска новых соединений, препятствующих их накоплению.

Ключевые слова: конечные продукты гликирования, острое повреждение легких/острый респираторный дистресс-синдром, гриппозная инфекция. 


\section{Ввемение}

B период пандемии гриппозной инфекции, вызванной вирусом гриппа A/H1N1pdm09 в 2009 году, у больных с высокой частотой наблюдалось развитие ОПЛ и его наиболее тяжёлой формы - ОРДС [1; 2]. При этом несмотря на специфическую этио- и патогенетическую терапию доля летальных исходов доходила до $30 \%$ [3; 4].

В связи с этим продолжается поиск новых средств фармакотерапии, направленных, в первую очередь, на ограничение системной воспалительной реакции, как основного патогенетического звена ОПЛ/ОРДС [5-9]. В настоящее время известно, что наряду с Толл-подобными рецепторами и рецепторами цитокинов, существенное провоспалительное действие оказывают конечные продукты гликирования [10-12]. Последнее подразумевает необходимость поиска возможных путей коррекции их накопления. Так, была показана позитивная роль ряда блокаторов данного процесса при моделировании каррагинанового локального воспаления, паразитарной инфекции, КПГ-опосредованного аортита [13-15]. В основе механизма их действия может лежать как прямое связывание промежуточных продуктов гликирования путём образования ковалентных связей (аминогуанидин, 2,3-диаминофеназин, ОРВ-9195) [16], так и предотвращение самоокисления глицеральдегид-3-фосфата до метилглиоксаля (основного предшественника КПГ) (пиридоксин, тиамин, бенфотиамин) [16; 17]. При этом тиамин и бенфотиамин сдвигают процесс утилизации молекулы глюкозы в сторону пентозо-фосфатного пути за счет активации тиамин-зависимой транскетолазы [18], а пиридоксин и его метаболиты пиридоксаль и пиридоксаль фосфат способствуют снижению выраженности оксидативного стресса путём связывания свободных гидроксильных радикалов (•ОН) [19-20]. Накопление последних в митохондриях вызывает снижение активности глицеральдегид-3-фосфат дегидрогеназы, что приводит к замедлению ферментативной утилизации субстрата [16].

Целью настоящей работы являлось сравнительное изучение эффективности блокаторов накопления КПГ различного механизма действия при заражении мышей вирусом гриппа A/H1N1pdm09 в дозе, равной 1 ЛД50.

\section{Материалы и метомы}

Эксперименты были проведены на беспородных мышах $(n=135)$, полученных из ФГУП «Питомник лабораторных животных «Рапполово» РАН (Ленинградская область)». Все манипуляции осуществляли в соответствии с директивой 2010/63/EU Европейского парламента и Европейского союза по охране животных, используе- мых в научных целях (Rus-LASA, 2012). Проведение работы одобрено на заседании этического комитета ФГБУ «НИИ гриппа им. А.А. Смородинцева» Минздрава России» (протокол № 100 от 15.12.2015).

ОПЛ моделировали путём интраназальной инокуляции вируса гриппа штамма A/California/7/09 MA (H1N1) pdm09 в дозе, равной 1 LD50 (3,4 log10 EID), определённой в предварительных экспериментах по методике Рида-Менча [21]. Вирусную природу ОПЛ подтверждали постановкой реакции гемагглютинации по образованию характерного «зонтика» в смеси [22].

Экспериментальные животные были разделены на 4 группы: группа № $1 \square$ интактные животные ( $\mathrm{n=15}$ ); группа № $2 \square$ инфицированные мыши, получавшие подкожно (п/к) фосфатно-солевой буфер ( $\mathrm{n}=40)$; группа № 3 - инфицированные мыши, получавшие пиридоксина гидрохлорид п/к 25 мг/кг (n=40); группа № 4 - инфицированные мыши, получавшие аминогунидин бикарбонат п/к 25 мг/кг (n=40). Изучаемые соединения вводили в течение первых 7-ми дней после инфицирования. Животные внутри 2-й, 3-ей и 4-й группы были разделены на равные подгруппы. В первых подгруппах оценивали уровень летальности. Во вторых подгруппах часть животных подвергали плановой эвтаназии на 4-е и 7-е сутки после инфицирования с целью забора биоматериала. Оценку уровня сатурации гемоглобина крови кислородом проводили по методике Джонкинса [23]. Оценку оптической плотности растворов гемоглобина осуществляли на приборе АБхФк-02-«НПП-ТМ» (Россия). Концентрацию КПГ определяли путём оценки уровня флуоресценции супернатанта гомогената лёгких при длинах волн: $\lambda e x=360$ нм, $\lambda e m=440$ нм на флуоресцентном модуле прибора CLARIOstar (Германия) [24]. Легкие животных после плановой эвтаназии фиксировали в 10\% формалине $(\mathrm{pH}=7,4)$, срезы окрашивали гематоксилин-эозином [25]. Степень поражения лёгких оценивали по методике [26], заключающейся в подсчёте типовых патоморфологических проявлений ОПЛ/ОРДС, наблюдаемых при микроскопировании гистологических препаратов в 20 полях при увеличении ×400, с последующим присвоением баллов. Выраженность повреждения оценивали по формуле 1.

$$
\begin{aligned}
& \text { Степень поражения }= \\
& =\frac{(20 \cdot \mathrm{A})+(14 \cdot \mathrm{B})+(7 \cdot \mathrm{C})+(7 \cdot \mathrm{D})+(2 \cdot \mathrm{E})}{\text { количество просмотренньг полей } \cdot 100},
\end{aligned}
$$

где А (количество нейтрофилов в альвеолах), В (количество нейтрофилов в интерстиции), С (количество гиалиновых мембран), D (наличие белкового дебриса в воздушном пространстве), Е (утолщение альвеолярной перегородки). 


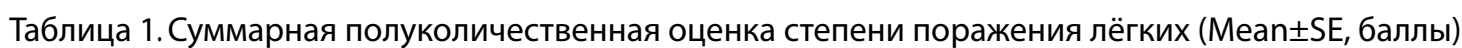

\begin{tabular}{|c|c|c|c|c|c|c|c|}
\hline \multirow{3}{*}{$\begin{array}{l}\text { Изучаемые } \\
\text { показатели } \\
\text { (Mean士SE) }\end{array}$} & \multirow{3}{*}{$\begin{array}{l}\text { Интактные } \\
\text { (гр. № 1) } \\
\text { (n=15) }\end{array}$} & \multicolumn{6}{|c|}{ Опытные группы и сроки исследования } \\
\hline & & \multicolumn{3}{|l|}{4 сутки } & \multicolumn{3}{|l|}{7 сутки } \\
\hline & & $\begin{array}{l}\text { Гр.№ } 2 \\
(n=5)\end{array}$ & $\begin{array}{l}\text { Гp.№ } 3 \\
(n=5)\end{array}$ & $\begin{array}{l}\text { Гp.№ } 4 \\
(n=5)\end{array}$ & $\begin{array}{l}\text { Гр.№ } 2 \\
(n=5)\end{array}$ & $\begin{array}{l}\text { Гp.№ } 3 \\
(n=5)\end{array}$ & \begin{tabular}{|l|} 
Гp.№ 4 \\
$(n=5)$
\end{tabular} \\
\hline $\begin{array}{l}\text { Суммарная оценка, } \\
\text { баллы }\end{array}$ & $\begin{array}{l}0,06 \pm \\
0,00\end{array}$ & $\begin{array}{l}0,39 \pm \\
0,02 *\end{array}$ & $\begin{array}{l}0,37 \pm \\
0,01 *\end{array}$ & $\begin{array}{l}0,35 \pm \\
0,01 * \#\end{array}$ & $\begin{array}{l}0,67 \pm \\
0,01 *\end{array}$ & $\begin{array}{l}0,63 \pm \\
0,01 * \#\end{array}$ & $\begin{array}{l}0,56 \pm \\
0,01 * \# \$\end{array}$ \\
\hline
\end{tabular}

Примечание: * - p<0,05 по отношению к группе № 1; — $-p<0,05$ по отношению к группе № 2; \$ $\mathrm{p}<0,05$ по отношению к группе № 3 Сравнения приведены внутри своего временного отрезка.

Гр.№ 1 - интактные мыши (n=15); Гр.№ 2 - инфицированные мыши, получавшие фосфатно-солевой буфер; Гр.№ 3 - инфицированные мыши, получавшие пиридоксина гидрохлорид; Гр.№ 4 инфицированные мыши, получавшие аминогуанидина бикарбонат).

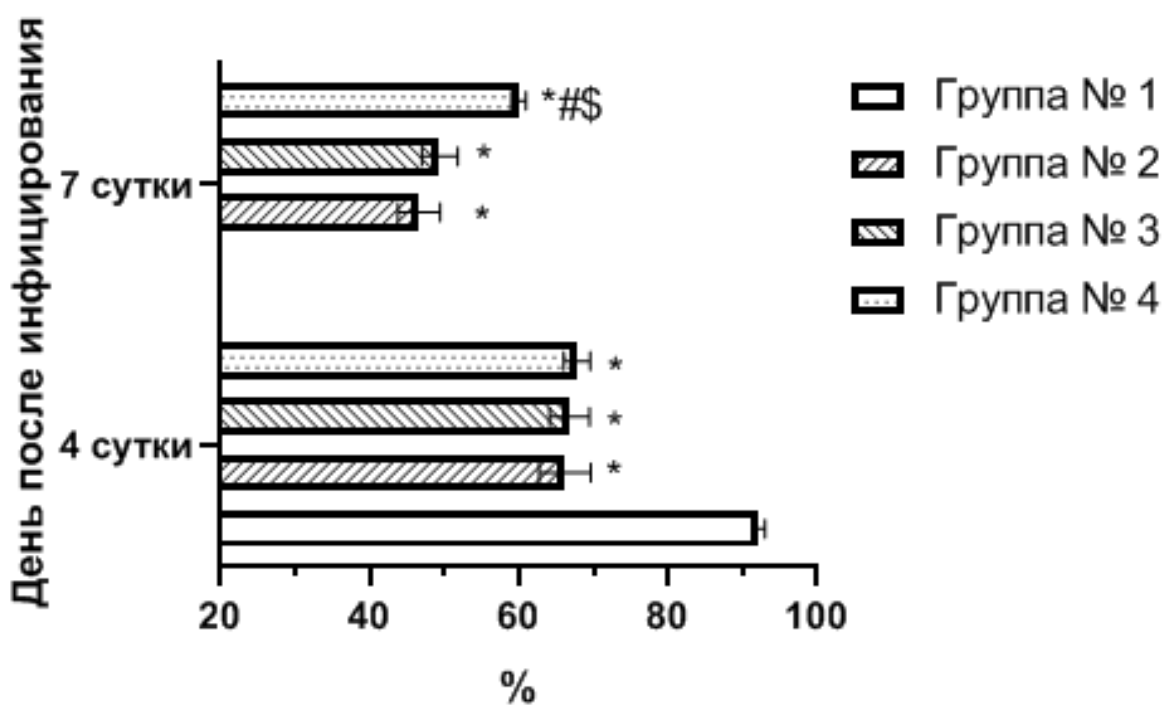

Рис. 1. Динамика изменения уровня сатурации гемоглобина крови кислородом (\%)

* - p $<0,05$ по отношению к группе № 1 ; \# - p<0,05 по отношению к группе № 2; \$ - p<0,05

по отношению к группе № 3. Сравнения приведены внутри своего временного отрезка ( $\mathrm{n}=5$ в каждой опытной группе).

Гр.1 - интактные мыши (группа № 1, n=15); Гр.2 - инфицированные мыши, получавшие фосфатносолевой буфер (группа № 2); Гр.3 - инфицированные мыши, получавшие пиридоксина гидрохлорид (группа № 3); Гр.4 - инфицированные мыши, получавшие аминогуанидина бикарбонат (группа № 4).

Оценку статистической значимости различий проводили при помощи программы Graphpad Prism 8. Для регистрируемых количественных параметров рассчитывали показатели описательной статистики, включавшие в себя среднее арифметическое значение параметра в группе (Mean), стандартное отклонение параметра (Std.Dev., SD), стандартную ошибку среднего (Std.Err., SE), 25-й и 75-й процентили. Для оценки различий между выборками применяли тесты Краскела-Уоллиса и МаннаУитни. Представленные в таблице и на рисунках данные указаны в виде среднего арифметического и его ошибки (Mean \pm SE). Достоверность различий вычисляли с помощью критерия Мантела-Кокса. Различия считали статистически значимыми при $\mathrm{p}<0,05$ [27].

\section{Результаты и их обсужАение}

Гибель животных после заражения наблюдалась, начиная с 5-х по 10-е сутки во всех опытных группах. Общая выживаемость в течение эксперимента составила 35\% в группе № 2, 65\% ( $p=0,1003)$ - в группе, получавшей пиридоксина гидрохлорид, и 70\% ( $p=0,0469)$ - в группе, получавшей аминогуанидина бикарбонат.

Анализ показателей, характеризующих развитие ОПЛ/ОРДС, продемонстрировал прогредиентное снижение уровня сатурации гемоглобина крови кислородом на 30\% и на 50\% (рисунок 1) и увеличение степени повреждения легких в 6,5 и 11,2 раз на 4-е и 7-е сутки после 


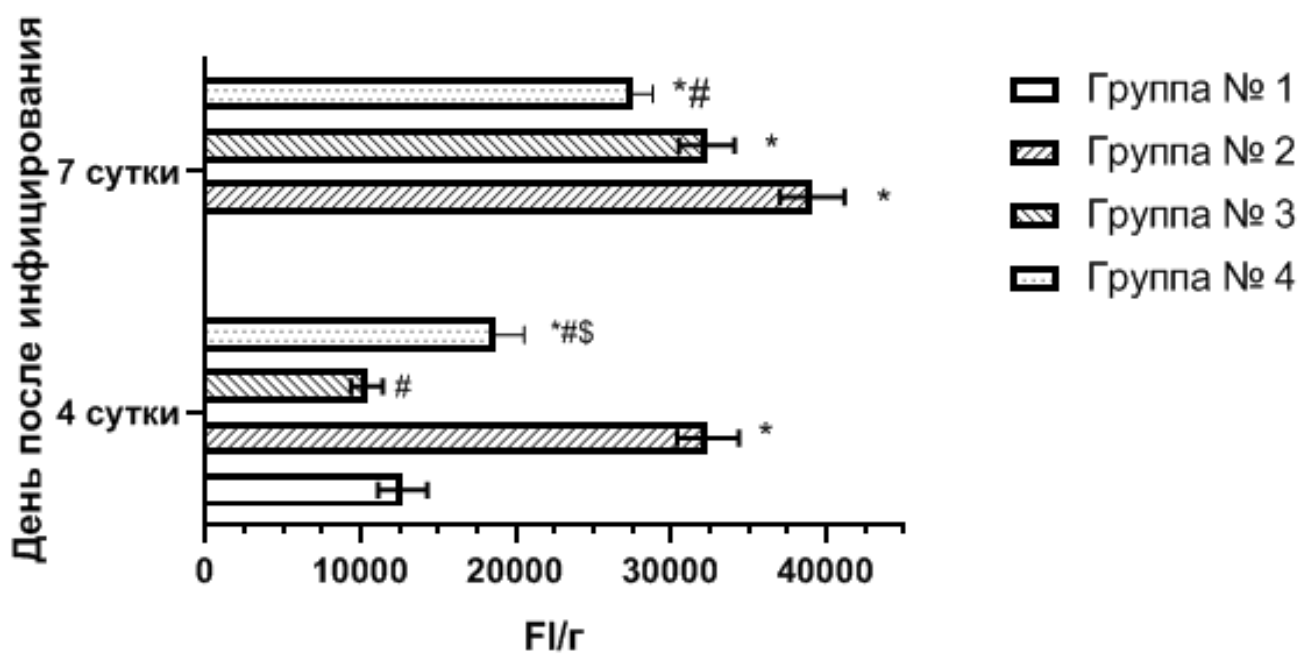

Рис. 2. Динамика накопления КПГ в ткани лёгких (Fl/г).

* - p<0,05 по отношению к группе № 1 ; \# - p<0,05 по отношению к группе № $2 ; \$-p<0,05$

по отношению к группе № 3. Сравнения приведены внутри своего временного отрезка ( $n=5$ в каждой опытной группе).

Гр.1 - интактные мыши (группа № 1, n=15); Гр.2 - инфицированные мыши, получавшие фосфатносолевой буфер (группа № 2, n=5); Гр.3 - инфицированные мыши, получавшие пиридоксин (группа № 3, $\mathrm{n=5);} \mathrm{Гр.4} \mathrm{-} \mathrm{инфицированные} \mathrm{мыши,} \mathrm{получавшие} \mathrm{аминогуанидин} \mathrm{(группа} \mathrm{№} \mathrm{4,} \mathrm{n=5).}$

инфицирования, соответственно (таблица 1) у животных из контрольной группы (фосфатно-солевой буфер). Аналогичная картина наблюдалась и в отношении нарастания содержания КПГ в легких (рисунок 2).

Анализ влияния изучаемых соединений на степень гипоксии продемонстрировал, что на 4-е сутки эксперимента у животных, получавших как аминогуанидина бикарбонат, так и пиридоксина гидрохлорид, уровень сатурации гемоглобина кислородом не отличался от такового у инфицированных мышей из группы № 2 и был значимо ниже, чем у интактных особей (рисунок 1). На 7-е сутки эксперимента в группе животных, получавших пиридоксина гидрохлорид, имело место дальнейшее снижение значения данного показателя аналогично таковому у особей из контрольной группы (группа № 2). Аминогуанидина бикарбонат, при этом, практически предотвратил прогредиентное снижение уровня сатурации гемоглобина кислородом $(p=0,0079)$ по отношению к контрольным животным.

Оценка влияния изучаемых соединений на степень повреждения лёгочной паренхимы показала, что в условиях применения аминогуанидина бикарбоната наблюдалось ограничение данного процесса на 4-е и, максимально, на 7-е сутки ( $p=0,0159$ и $p=0,0079$, соответственно, по отношению к животным из группы № 2, в отличие от пиридоксина гидрохлорида, значимое протективное действие которого имело место только к окончанию эксперимента ( $p=0,0317)$. При этом на данном этапе развития патологии аминогуанидина бикарбонат по своей эффективности значимо превосходил пиридоксина гидрохлорид. Таким образом, по совокупности типовых показателей, характеризующих развитие ОПЛ/ОРДС, аминогуанидин бикарбонат проявил более выраженные протективные свойства, чем пиридоксина гидрохлорид.

Применение обоих изучаемых соединений привело К неоднозначному ограничению роста КПГ на различных сроках формирования ОПЛ/ОРДС. Так, на 4-е сутки эксперимента у животных, получавших пиридоксина гидрохлорид, рост уровня КПГ в легких отсутствовал ( $p=0,0079)$, в то время как применение аминогуанидина способствовало частичному ограничению прироста их концентрации (в 3,3 раза по отношению к контрольным животным, $p=0,0079)$. На 7-е сутки эксперимента в обеих группах животных, получавших изучаемые соединения, наблюдалось дальнейшее повышение уровня КПГ по отношению к интактным особям. При этом степень выраженности данного показателя только у мышей, которым вводили аминогуанидина бикарбонат, была значимо ниже в сравнении с животными из контрольной группы $((p=0,0079)$.

Выявленные различия в действии изучаемых соединений на уровень КПГ на начальном и последующем этапах формирования ОПЛ/ОРДС могут быть связаны 
с особенностями механизма их воздействия на процесс накопления данных продуктов. Так, в основе действия пиридоксина гидрохлорида лежит связывание свободных гидроксильных радикалов, рост которых приобретает «взрывной» характер по мере усугубления повреждения легких вследствие чрезмерной генерации их фагоцитами, с одной стороны, и развивающейся функциональной недостаточностью антиоксидантной защиты, с другой стороны [28]. Этим можно объяснить эффективность данного соединения в отношении накопления КПГ на начальном этапе формирования патологии и нивелирование такового действия в дальнейшем. Аминогуанидина бикарбонат предотвращает накопление КПГ путем образования ковалентных связей с промежуточными продуктами гли- кирования (в частности, с продуктами реакции Амадори). По-видимому, в этом случае влияние окислительного стресса на данный процесс не играет существенной роли [16], что и объясняет возрастающую эффективность аминогуанидина бикарбоната по мере увеличения продолжительности введения опытным животным.

\section{Зак^ючение}

Полученные результаты являются основанием для дальнейшего изучения возможности применения блокаторов образования КПГ различного механизма действия с целью коррекции течения экспериментального ОПЛ/ОРДС вирусного генеза.

\section{ЛИТЕРАТУРА}

1. Quispe-Laime A.M. H1N1 influenza A virus-associated acute lung injury: response to combination oseltamivir and prolonged corticosteroid treatment / A. M. QuispeLaime, J. D. Bracco, P. A. Barberio [et al] // Intensive Care Med, 2010. — Vol. 36, P. 33-41, doi: 10.1007/s00134-009-1727-6.

2. Yokoyama T. Case series of ALI/ARDS due to the novel influenza virus infection / T. Yokoyama, K. Kubo // Japanese Journal of Chest Diseases, 2010. — Vol. 69, Iss. 12, P. 1096-1102.

3. Всемирная организация здравоохранения [Электронный ресурс] — Режим доступа: https://www.who.int/csr/resources/publications/swineflu/h1n1_ guidelines_pharmaceutical_mngt.pdf — Заглавие с экрана (Дата обращения 01.08.19).

4. Clinical management of human infection with pandemic (H1N1) 2009: revised guidance [Электронный ресурс] — Режим доступа: https://www.who.int/csr/ resources/publications/swineflu/clinical_management_h1n1.pdf — Заглавие с экрана (Дата обращения 23.09.2019)

5. Han S. The acute respiratory distress syndrome: from mechanism to translation / S. Han, R. K. Mallampalli // Journal of immunology, 2015. — Vol.194, Iss.3, P. 855860, doi: 10.4049/jimmunol.1402513.

6. Samra T. Comparative evaluation of acute respiratory distress syndrome in patients with and without H1N1 infection at a tertiary care referral center/ T. Samra, M. Pawar and A. Yadav// Indian Journal of Anaesthesia, 2011. — Vol. 55, Iss. 1, P. 47-51, doi: 10.4103/0019-5049.76602.

7. Clowes G. H.A. Septic Lung and Shock Lung in Man/ G.H.A. Clowes, E. Hirsch, L. Williams [et al] // Annals of Surgery, 1975.— Vol. 181, Iss. 5, P. 681-692, doi: 10.1097/00000658-197505000-00024.

8. Bernard G. R. The American-European Consensus Conference on ARDS. Definitions, mechanisms, relevant outcomes, and clinical trial coordination / G. R. Bernard, A. Artigas, K. L. Brigham [et al] // American Journal of Respiratory and Critical Care Medicine, 1994.—Vol. 149, Iss. 3, P.818-824, doi: 10.1164/ajrccm.149.3.7509706.

9. Ferguson N. D. The Berlin definition of ARDS: an expanded rationale, justification, and supplementary material / N. D. Ferguson, E. Fan, L. Camporota [et al] // Intensive Care Medicine, 2012.—Vol. 38, Iss. 10, P. 1573-1582, doi: 10.1007/s00134-012-2682-1.

10. Kierdorf K. RAGE regulation and signaling in inflammation and beyond / K. Kierdorf, G. Fritz // Journal Leukocyte Biology, 2013 — Vol. 94, Iss. 1, P. 55-68, doi: 10.1189/jlb.1012519.

11. Davis K. E. Advanced Glycation End Products, Inflammation, and Chronic Metabolic Diseases: Links in a Chain?/ K. E. Davis, Ch. Prasad, P. Vijayagopal [et al] // Critical Reviews in Food Science and Nutrition, 2014. — Vol.56, Iss.6, P. 989-998, doi: 10.1080/10408398.2012.744738.

12. Успенская Ю. А. Рецепторы конечных продуктов гликирования белков RAGE: лиганды, биологические эффекты и роль в нейродегенерации / Ю. А. Успенская, Я. В. Горина, В. В. Салмин [и др.] // Вестник Новосибирского гос. ун-та. Серия: Биология, клиническая медицина, 2014. — Т. 12, Вып. 4. С. $68-76$.

13. Dudhgaonkar S. P. Synergistic anti-inflammatory interaction between meloxicam and aminoguanidine hydrochloride in carrageenan-induced acute inflammation in rats / S. P. Dudhgaonkar, S. K. Tandan,, A. S. Bhat [et al]// Life Sciences, 2006. — Vol.78, Iss.10, P. 1044-1048, doi:10.1016/j.lfs.2005.06.002.

14. Kołodziej-Sobocińska M. In vivo inhibition of inducible nitric oxide synthase by aminoguanidine influences free radicals production and macrophage activity in Trichinella spiralis infected low responders (C57BL/6) and high responders (BALB/C) mice / M. Kołodziej-Sobocińska, B. Machnicka-Rowińska // Helminthologia 49, 189-200 (2012). doi: 10.2478/s11687-012-0038-6.

15. Matsui T. Sulforaphane reduces advanced glycation end products (AGEs)-induced inflammation in endothelial cells and rat aorta / T. Matsui, N. Nakamura, A. 0jima [et al] // Nutrition, Metabolism and Cardiovascular Diseases, 2016. — Vol.26, Iss.9, P. 797-807, doi:10.1016/j.numecd.2016.04.008.

16. Nagai R. Chelation: a fundamental mechanism of action of AGE inhibitors, AGE breakers, and other inhibitors of diabetes complications / R. Nagai, D. B. Murray, T. 0. Metz [et al] // Diabetes, 2012.—Vol.61, Iss.3, P. 549-559, doi:10.2337/db11-1120.

17. Velásquez M. Pyridoxine Decreases Oxidative Stress on Human Erythrocyte Membrane Protein in vitro / M. Velásquez, D. Méndez, C. Moneriz//The Open Biochemistry Journal, 2019. — Vol. 13, P. 37-44. doi: 10.2174/1874091X01913010037.

18. Balakumar P. The multifaceted therapeutic potential of benfotiamine / P. Balakumar, A. Rohilla, P. Krishan [et al] // Pharmacological Research, 2010. — Vol.61, Iss. 6, P. 482-488. doi:10.1016/j.phrs.2010.02.008. 
19. Hu M.-L. The antioxidant and prooxidant activity of some B vitamins and vitamin-like compounds / M.-L. Hu, Y.-K. Chen \& Y.-F. Lin// Chemico-Biological Interactions, 1995. — Vol.97, Iss.1, P. 63-73, doi:10.1016/0009-2797(95)03608-8.

20. Taş S Vitamin B6 supplementation improves oxidative stress and enhances serum paraoxonase/arylesterase activities in streptozotocin-induced diabetic rats / $\mathrm{S}$. Taş, E. Sarandöl, M. Dirican // Scientific World Journal, 2014.—Vol.2014, Article ID351598, doi:10.1155/2014/351598.

21. Burleson F.G. Introduction to quantal virus assays / F.G. Burleson, T.M. Chambers, D. L. Wiedbank // In: Virology: a laboratory manual /eds. F.G. Burleson, T. M. Chambers, D. L. Wiedbrauk. — Academic Press, San Diego, 1991. — P. 53-57.

22. Ожередова Н. А. Общая вирусология: Методические указания / Н. А. Ожередова, М. Н. Веревкин, Е. В. Светлакова- Ставрополь: АГРУС, 2013. 囚5 С.

23. Jonxis J. H.P. The determination of oxygen saturation in small amounts of blood, by means of the Pulfrich step photometer / J.H.P. Jonxis// Acta Medica Scandinavica, 1943. - Vol.115, Iss.5, P. 425-428, doi:10.1111/j.0954-6820.1943.tb15858.x.

24. Yanagisawa K. Specific fluorescence assay for advanced glycation end products in blood and urine of diabetic patients / K. Yanagisawa, Z. Makita, K. Shiroshita [et al] // Metabolism, 1998. — Vol. 47, Iss. 11, P. 1348-1353, doi:10.1016/s0026-0495(98)90303-1.

25. Коржевский Д. Э. Основы гистологической техники / Д. Э. Коржевский, А. В. Гиляров.—СПб: СпецЛит, 2010. — 95 с.

26. Matute-Bello G. An official American Thoracic Society workshop report: features and measurements of experimental acute lung injury in animals / G. Matute-Bello, G. Downey, B. B. Moore [et al] // American journal of respiratory cell and molecular biology, 2011.—Vol.44, Iss.5, P. 725-738, doi:10.1165/rcmb.2009-0210ST

27. Гланц С. Медико-биологическая статистика / Гланц С.; пер. с англ.—М., Практика, 1998. — 459 с.

28. Соодаева С. К. Свободно-радикальные механизмы повреждения при болезнях органов дыхания / С. К. Соодаева // Пульмонология, 2012. - Вып.1, C. 5-10, doi:10.18093/0869-0189-2012-0-1-5-10.

(с) Александров Андрей Георгиевич ( forphchemistry@gmail.com ),

Саватеева-Любимова Татьяна Николаевна ( drug_safety@mail.ru ),Жилинская Ирина Николаевна ( irina.zhilinskaya@influenza.spb.ru ).

Журнал «Современная наука: актуальные проблемы теории и практики»

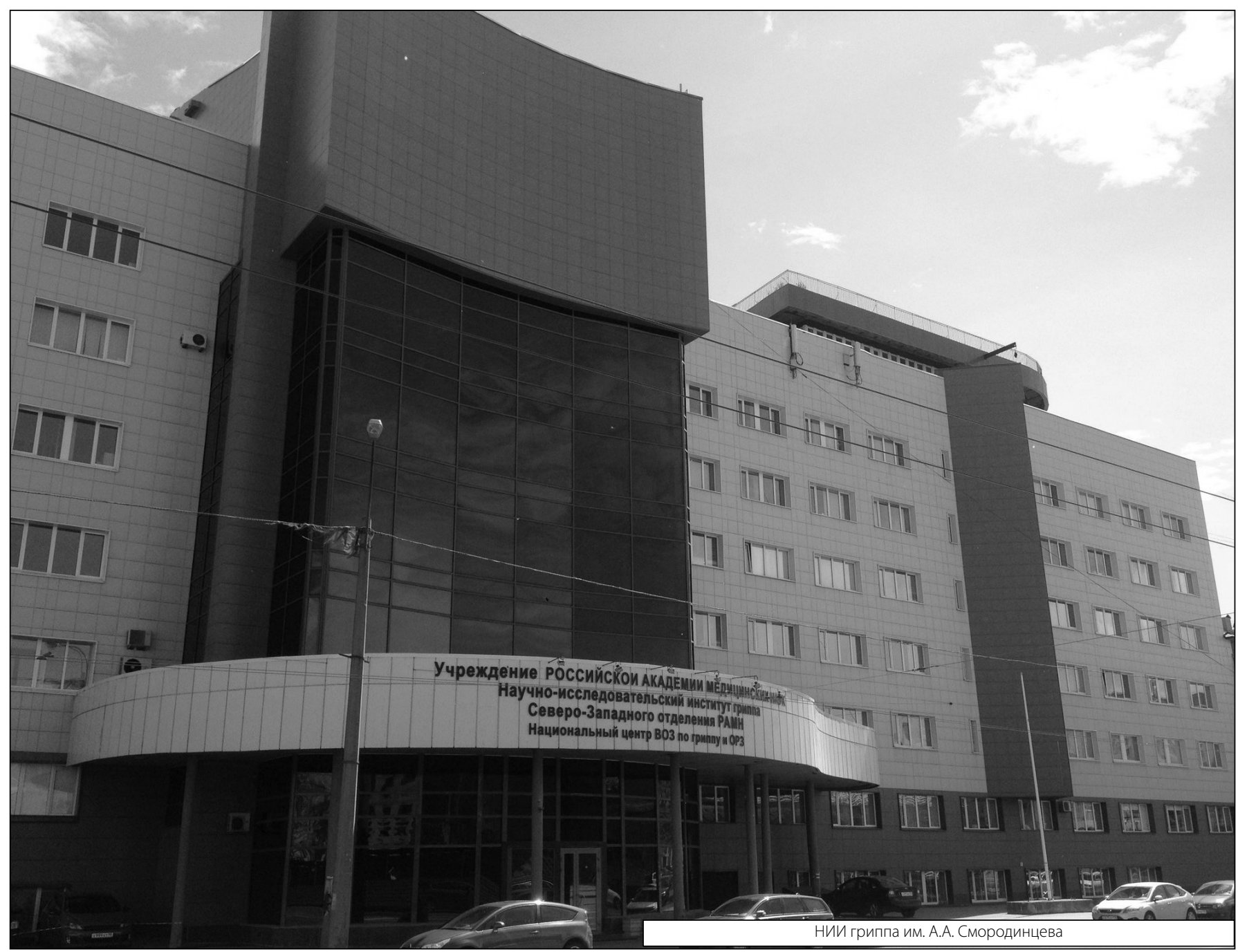

